facturers might be cheaper and simpler even if it entailed an element of subsidy.

A survey by A. Cartwright and M. Waite ${ }^{4}$ showed that though general practitioners are advising their patients about birth control more than formerly the type of help and service they give is limited. This is not surprising when only $12 \%$ of those doctors who took part in the survey had had any training in family planning. The shortcomings in the teaching of it in undergraduate medical schools are slowly being overcome.

At the symposium different levels of postgraduate training were suggested: refresher courses for interested doctors; a detailed training programme as proposed by the joint committee of the Royal College of Obstetricians and Gynaecologists and the Royal College of General Practitioners to achieve a certificate in contraceptive practice; and a higher qualification for instructors.

The reorganization of the Health Service has meant that for the first time family planning is to be incorporated in it. Guidance on organization and finance is urgently needed. Simply to provide doctors and clinics with pills and devices is not enough.

\footnotetext{
1 A report is to be published by the Department of Human Reproduction and Obstetrics, Southampton Medical School, 125 Tremona Road, Southampton SO1 6HU.

2 Cartwright, A., Parents and Family Planning Services. London, Routledge and Kegan Paul, 1970.

3 Bone, M., Family Planning Services in England and Wales. London, H.M.S.O., 1973.

4 Cartwright, A., and Waite, M., Fournal of the Royal College of General Practitioners, 1972, 22, suppl. 2.
}

\section{Preleukaemic Syndrome}

Most patients with acute myeloblastic leukaemia show, on clinical presentation, diagnostic haematological abnormalities. There is, however, a small but important group in whom the diagnosis at the onset is obscure because the clinical and haematological features lack specificity yet who go on to develop frank acute leukaemia after a variable period of months or years.

The term preleukaemia was introduced by $M$. Block and colleagues $^{1}$ in 1953 to describe the haematological abnormalities which precede the development of acute myeloblastic or myelomonocytic leukaemia. Similar appearances in the blood had been considered earlier in the French literature ${ }^{2}$ and by J. L. Hamilton-Paterson, ${ }^{3}$ who proposed the term preleukaemic anaemia. Not included in the term preleukaemia are those haematological diseases such as chronic granulocytic leukaemia, which usually transforms to acute myeloblastic leukaemia; and myelofibrosis and polycythaemia rubra vera, which may transform.

By definition, the diagnosis of preleukaemia can be made only retrospectively. Numerous reports of preleukaemic states have appeared in the last 20 years, and the syndrome is now well recognized. ${ }^{4}$ M. I. Saarni and J. W. Linman ${ }^{5}$ have recently reviewed the literature and have added 34 cases of their own. The dominant haematological findings are anaemia, neutropenia, and thrombocytopenia, either together or, less commonly, singly or in varying combination. Related symptoms are undue breathlessness on exertion from the anaemia, recurrent bacterial infections from the neutropenia, and purpura and bruising from the thrombocytopenia. The spleen may be slightly enlarged but often is not palpable.

The anaemia is of mild to moderate severity, usually normocytic and normochromic, but the red cells vary in size and shape, macrocytes may be present, and there may be an admixture of hypochromic microcytic cells. Careful examination may show a few nucleated red cells in the blood film. The reticulocyte count is usually normal or only slightly raised. The anaemia does not respond to treatment with the recognized haematinic agents and has therefore been described as refractory.

The leucocyte count in most cases has been low, between 1,000 and $4,000 / \mu l$, and only occasionally have high counts been reported. Neutropenia accounts for the leucopenia. On the blood film the neutrophils may appear agranular and may show a Pelger-Huet-like anomaly - that is, the nucleus, though morphologically mature, may show only one or two lobes. A few myelocytes may be seen but usually not blast cells. The neutrophil alkaline phosphatase score is low or normal. A monocytosis has often been reported. Apart from the thrombocytopenia, platelets of abnormal shape, size, and granularity have been observed. The proportion of fetal haemoglobin in the blood may be increased.

The bone marrow in most cases of preleukaemia is hypercellular, often owing to erythropoietic hyperplasia, but in some cases granulopoietic hyperplasia due to an increase in myelocytes dominates the picture. The proportion of myeloblasts is normal or only slightly increased. Patients with refractory anaemia have been reported whose marrow contained an appreciable excess of myeloblasts which persisted unchanged for years, a condition called smouldering leukaemia rather than preleukaemia. Megaloblastic or megaloblastoid features unresponsive to treatment with vitamin $B_{12}$ or folic acid have often been described. Stainable iron is usually abundant, and ringed sideroblasts may be a prominent feature. Pure red cell aplasia has occasionally been found. Megakaryocytes may be normal or decreased in number and abnormally small in size.

A hypocellular marrow has been found in about a quarter of the reported cases of preleukaemia. Most of these patients had received drugs such as sulphonamides, chloramphenicol, or phenylbutazone, or had been exposed to benzene or ionizing radiations. A few patients with paroxysmal nocturnal haemoglobinuria have developed acute myeloblastic leukaemia and it has been suggested that defects characteristic of this disorder should be looked for in the red cells in the preleukaemic syndrome.

Chromosomal abnormalities in the bone marrow cells appear to be frequent but variable in kind, most often affecting the $\mathrm{C}$ group of chromosomes. P. C. Nowell ${ }^{6}$ has suggested that an abnormal chromosome pattern in a patient with suspected preleukaemia heralds the imminent onset of frank acute leukaemia. The capacity of the bone marrow to form granulocytic colonies in culture appears to be deficient in patients with preleukaemia, showing a functional disturbance in granulopoiesis preceding the evolution to frank leukaemia. ${ }^{7}$

The clinical course of the preleukaemic syndrome is variable. Leukaemia became evident within six months in about a third of the reported patients and by two years in most of the remainder. Rarely, the preleukaemic phase has lasted longer than five years.

In their review Saarni and Linman ${ }^{5}$ found no report of attempts at treatment with antileukaemic drugs in the preleukaemic phase. This is not surprising in view of the difficulties of recognizing the preleukaemic state and the necessity for retrospective corroboration. Splenectomy is considered to be of little or no benefit.

Examples of the preleukaemic syndrome appear to have been labelled as refractory anaemia, sideroblastic anaemia, 
aplastic anaemia, hypersplenism, or paroxysmal nocturnal haemoglobinuria. However, care has to be taken in the use of the term preleukaemia as a diagnostic label implying inevitable progression to acute leukaemia since it can be substantiated only when the definite changes of acute leukaemia have developed. Though non-specific, the use of the term "refractory anaemia" may be preferable because it does not necessarily imply that the prognosis is like that of established acute leukaemia. Certainly a diagnosis of leukaemia should not be made if there is any doubt. Can a preleukaemic disorder be halted or reversed? Perhaps a more thorough study of the preleukaemic state may help to provide an answer.

' Block, M., Jacobson, L. O., and Bethard, W. F., fournal of the American

Medical Association, 1953, 152, 1018.
2 Paraf, A., Revue d'Hématologie, 1949, 4, 655.

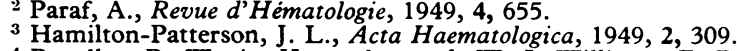

3 Hamilton-Patterson, J. L., Acta Haematologica, 1949, 2, 309.
Rundles, R. W., in Hematology, ed. W. J. Williams, E. Beutler, A. J. Ersley, and R. W. Rundles, p. 725. New York, McGraw-Hill Book

${ }^{5}$ Caarni, M. I., and Linman, J. W., American fournal of Medicine, 1973, $55,38$.

6 Nowell, P. C., Cancer, 1971, 28, 513.

7 Senn, J. S., and Pinkerton, P. H., British fournal of Haematology, 1972, 23, 277.

\section{The Christmas Pudding}

The time may not be far off when only scholars and their like, who retain childhood's power of confusing the symbol with reality and bringing it to life, will understand what was meant by a "groaning board." Libraries will be combed for dusty cookery books; an egg-stained page will evoke the same thrill as do De Quincey's manuscripts stained here and there with circles of laudanum where he put down his tumbler. A particularly fine recipe will be hailed as evidence of an art now lost, like that of colouring mediaeval cathedral glass. The following recipe indicates how rewarding such a pursuit might be:

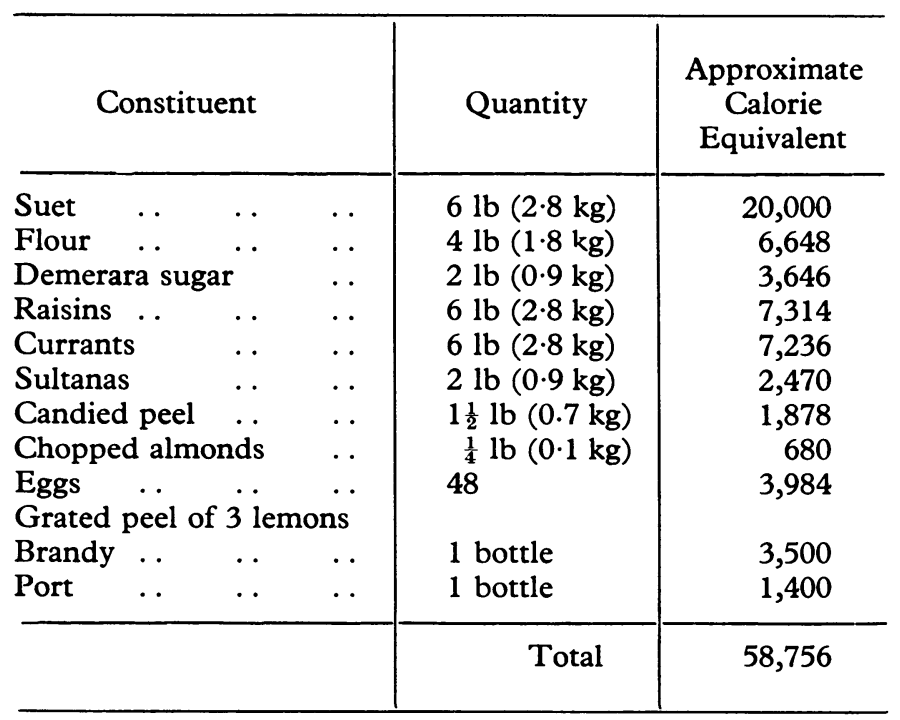

To compound fifty-five thousand calories (allowing for wastage in cooking) in a single pudding seems almost inconceivable in an age when we more readily concentrate them in a bomb. The present daily calorie intake per head is, on the average, about 2,750, or one-twentieth of the pudding-a portion that might well be eaten in a single large helping. But who cares about the calorie-content of such a creation? Its sustenance is of the spirit, not of the body. The mind is enriched and tranquil after such a meal, free to dream peacefully of those sunlit lands far over the blue, untaxable sea where grapes turn to wizened raisins in a day and the orange ripens. And what more appropriate to the season's international concord than the pudding's constituents?-brandy from France, the West Indies' sugar, almonds from Italy, lemons from the Levant, and Portugal's wine. From hurrying to gain "the poor benefit of a bewildering minute" life slows after such a dinner to a human pace. For just as our hearts quicken at the expense of diastole, our hastened lives have lost much relaxation and leisure. It is the function of Christmas puddings to restore this indispensable refreshment.

If we stress the cultural qualities of the Christmas pudding rather than the nutritional it is because they are more likely to be overlooked. The metabolic implications of such a mountain of food are too obvious and those of the palate too tantalizing to dwell, to dilate, upon further. We turn, rather, to the question of whether scarcity of food will cause us to revert to a more primitive state. Preoccupation with food, the mark of primitive societies, is certainly characteristic of our own today. It was once a common practice all over the world for the tribe to kill its king if the food supply failed; we threaten Governments nowadays. In time of dearth the Mexican Indians propitiated the gods with human sacrifices; we dispatch Ministers. The ritualistic dances and prayers of former times have given way to queueing and form-filling, petitions through trade union channels, and certificates from doctors; and the passion that introduces the topic of food into every conversation once filled the caves of Southern France with paintings of bison and deer. The old charms and formulae have come back to us in a new guise.

Dr. Johnson would today find ample evidence for his declaration that "human life is everywhere a state in which much is to be endured and little to be enjoyed." Our reduced Christmas pudding is as much a sign of the times as is our swollen Civil Service. Circumstance forces restrictions upon us; perhaps we shall in time become conditioned, like the rats, to finding our way quickly through the maze. More fearful, however, than the shrivelling of our pudding is the speculation whether it may at some time be forbidden altogether-a calamity that did occur once. In 1644 a Puritan Government prohibited the observance of Christmas by Act of Parliament. This must be a tempting precedent to our modern Puritans, and we shall watch developments closely. Meanwhile the season is here; the shops have been emptied and the stockings filled; and doctors will soon be dealing with the wish-bones, beads, sixpences, and tin soldiers that children cram down their throats whether there is a pudding to follow or not. A merry Christmas! 